\title{
Innovative computer technologies as an implementer of active methods of training
}

\author{
Oksana N. Efremova ${ }^{1, a}$,Tatyana O. Ivanova ${ }^{1}$,Inna V. Plotnikova ${ }^{1}$, Olga N. Chaykovskaya ${ }^{2}$ \\ ${ }^{1}$ Tomsk Polytechnic University, 634050 Lenin Avenue, 30, Tomsk, Russia \\ ${ }^{2}$ Tomsk State University, 634050 Lenin Avenue, 36, Tomsk, Russia
}

\begin{abstract}
Introduction of computer means in high schools is dictated by innovative processes in education. One of the latest innovations is Moodle, an open source web-based platform that provides a virtual learning environment. The article describes the arrangement of students' learning at the technical university with the help of didactic materials placed on the Moodle platform. The experimental work has shown that the organization of learning by means of the virtual learning environment had a positive effect on the level of training of first-year students. The survey conducted after the experiment completion allowed us to reveal the difficulties that students experienced during the work in the electronic environment, and, therefore, to plan the ways of their elimination.
\end{abstract}

\section{Introduction}

Introduction of innovations in education enables changes in the education system elements, such as: the qualification of the faculty; the motivation of teachers; the availability of education; the content of education (curricula and programs); the organizational structure of the educational process (forms and methods of organization, grading systems, ways of interaction between students and teachers).

The key role in modernization and development of innovations in education is allocated for the training based on computer technologies as one of the most effective forms of education. There is a widespread occurrence of such training both in foreign countries and in Russia.

Nevertheless Russian and foreign researchers note that the main emphasis in the organization of training with the use of computer technologies is placed on hardware. It should be noted that technical means of training alone cannot increase the quality of mastering training material. The student has to be involved in the educational and informative process through the full immersion in the information and education environment created by the applied software.

Nowadays, different types of software have been developed for the technical support of training. Surely, the development of the software focused on scientific and methodical support requires time, resources, and qualified specialists.

Over the last few years, many researchers have reported the application of interactive technologies to

\footnotetext{
${ }^{\mathrm{a}}$ Corresponding author: oks-efremova@yandex.ru
}

manage the independent learning and to train students remotely. The virtual learning environment (VLE) Moodle is the most popular open software package created for the teachers' effective organization of the online training, using a wide range of pedagogical principles. As a rule, Moodle is used in the educational process for distant learning of students.

The analysis of scientific and pedagogical sources on the implementation of innovations in education has been performed to determine the research priorities:

- the development of innovative educational programs $[1,2]$, the inclusion of new advances in study programs [3], between theory and practice [4], start-upproject applying videoconferences connecting campuses with homes [5];

- the usage of mobile applications (smartphones, iPads, laptops $[6,7,8,9,10]$;

- the usage of social networks [11], social media [12, $13,14]$ and the Internet $[15,16,17.18]$;

- the usage of Moodle [19, 20, 21, 22].

Let us note that nowadays the huge part of the education process is assigned to a teacher as a mediator and a designer of the training environment.

For example, [9] utilized the technical support in training to provide the teachers and students with support of a training course and to ensure a flexible web approach (web based approach) without the teacher's constant assistance.

The research is partially focused on the introduction of innovations in education by means of the mixed training (traditional training together with online training [23]. 
The research is related to the introduction of the Moodle platform in an educational process.

\section{Materials and methods}

To validate the stated ideas, we have conducted a research together with the first-year students on the basis of Tomsk Polytechnic University (TPU). The students of six groups and three lecturers participated in the experiment. In three control groups the process of independent learning was organized in a traditional way (students were assigned to do their homework in a notebook), and the other groups did their homework in the Moodle based training system.

The teacher's activity at the initial stage was focused on the development and placement of the didactic materials: slides for lectures, video lessons, home and control tasks in the form of tests, a rating-list, methodical instructions on performance of tasks, etc.

Before the experiment, the students have been surveyed. The purpose was to clarify the opinion of respondents on the need of computerization in studying mathematics and disciplines of a natural-science cycle. The survey of 105 first-year students revealed the following results: 82 students $(78 \%)$ considered computerization necessary for the educational process. They indicated that one of the ways to computerize the educational process was the electronic support of the course. It should be noted that most of the respondents $(70 \%)$ emphasized the necessity of the obligatory communication between students and teachers. Only $25 \%$ of respondents found the electronic testing on the course subjects appealing. The respondents emphasized that a test task is aimed to display ordinariness of thinking and gives no chance to manifest oneself in creativity.

At the second stage, the students independently worked with the tasks on mathematics placed on Moodle platform from their houses.

The students obtained access to training materials placed in the software environment (through personal password and login) to perform a set of tasks during the semester independently. The students performed a part of the tasks available at home via Moodle and uploaded them on the platform. After checking by the teacher, the task was handed to the student for completion. Doing the tests, students were able to view the assessment results and read the teacher's comments on mistakes. The open and closed types of tests, matching tasks, collaboration work were also offered to the students. Before doing homework, the student could study some information on the subject, learn what knowledge and abilities s/he would acquire after completing the task, and how each task would be assessed. Also, the student could revise the theoretical material, watch video lessons or slides to the lectures, and study sample solutions. Then the student started performing the tasks.

After the students completed the task, the teacher made the report on the marks, either due to the activities or users. The teacher could see at once what tasks caused difficulties for students and conduct the tutorial intended to reveal the reasons of the problems.

Let us consider the main advantages of Moodle:

- it can be loaded and used on any computer (including modern mobile devices) with an Internet browser;

- flexible organization of the educational process is possible due to the variation of methods, means and forms of data representation: material on the discipline is presented in the electronic course, which contains various multimedia information (graphics, audio, video) for the efficient learning of training material by the students; control tasks are offered at the end of each subject (questions for self-examination, tests, surveys);

- the tasks of various levels of complexity are provided to ensure the training process with due regard to the students' real knowledge;

-it is possible to create the block of adaptive testing for the current control, which provides the variability in presentation of tasks with due regard to the students' level of training;

- it gives opportunities for communication and interaction of participants of the educational process: discussion of topical issues on forums; informative and advisory feedback between students and teachers by means of the module of personal messages; virtual conferences in the form of a webinar; collaborative creation of electronic documents and training materials on the basis of wiki-technologies, databases, and blogs;

- it possesses the tools on collection, processing and storage of analytical and statistical information on almost all the events of educational process in the system: a web-based gradebook of the students' progress with all personal achievements to promote competitiveness in order to improve the results; all information on the activity of students in the system (attendance, list of the viewed materials, portfolios); an appropriate system of planning the training events to allow students to assess the educational activity and to timely correct the trajectory of their development;

- it helps each student consider the results of training and the ways of achieving personal progress.

A large amount of illustrative materials (images, audio, and video) allow students to fully understand the material.

The students of six groups (105 students) and three lecturers participated in the experiment. Each lecturer organized the independent work in one group in a traditional way, and in another group the process of independent learning was organized on the Moodle platform. The total amount of students in the experimental groups was 53 students, and 52 students were trained in the control groups. The entry test performed prior to the experiment showed that the level of basic knowledge on mathematics was almost identical in both groups.

At the final stage of the experiment (at the end of the academic year), the assessment of knowledge on the subject was carried out.

Let us consider the conversion of the grading system to different scales stated in the regulations of TPU.

A*: 96-100 - excellent; 

A: 90-95 - excellent;
B*: 80-89-good;
B: 70-79-good;
$C^{*}:$ 65-69 - satisfactory;
C: 55-64 - satisfactory;
F: 0 - 54 - poor.

The student's grade on the discipline consists of the points the student got during a semester and the points for the exam.

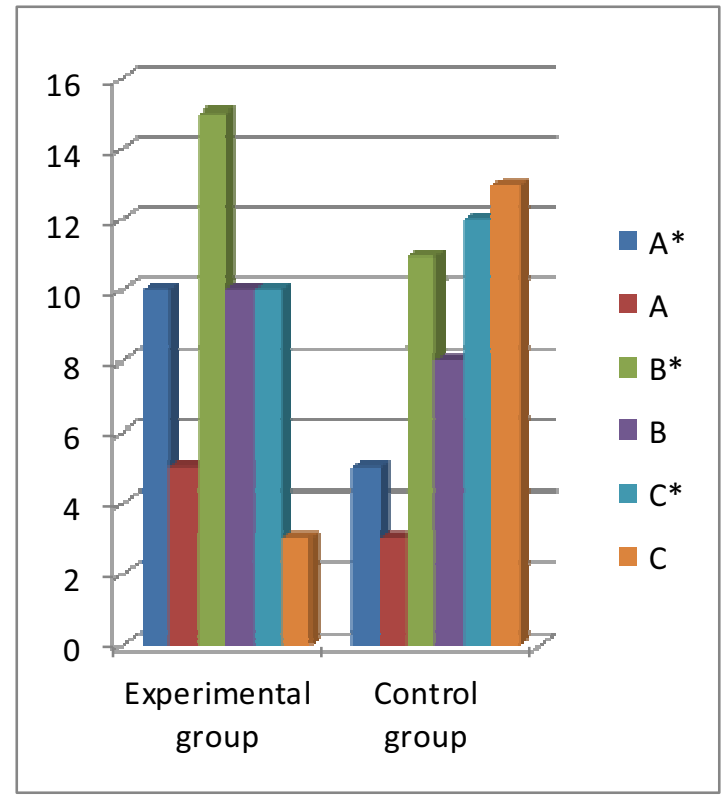

Fig. 1. Final grades for the course "Mathematics"

The analysis of the final grades for the course "Mathematics" showed that the level of knowledge of the experimental group was higher than that of the control group. Fifteen students $(28 \%)$ in the experimental group got excellent marks, and only eight students $(15 \%)$ got the same mark in the control group. Twenty five students (47\%) in the experimental group got good marks; in the control group good marks were received by nineteen students (36. 6\%). Finally, satisfactory marks were received by thirteen students $(25 \%)$ in the experimental group, and twenty five students (48\%) in the control group got the same marks.

After the experiment, the students were surveyed to reveal the degree of usefulness of certain opportunities of the electronic course "Mathematics".

The students could choose between the following options:

- yes, it is very useful;

- rather useful;

- rather useless;

- absolutely useless;

- I find it difficult to answer this question.

Due to a large number of the estimated parameters, only two parameters of the obtained survey results have been considered:

- useful (yes, it is very useful; it is rather useful);

- useless (it is rather useless, absolutely useless).

The results of the survey are presented in the form of a histogram (Figure 2).

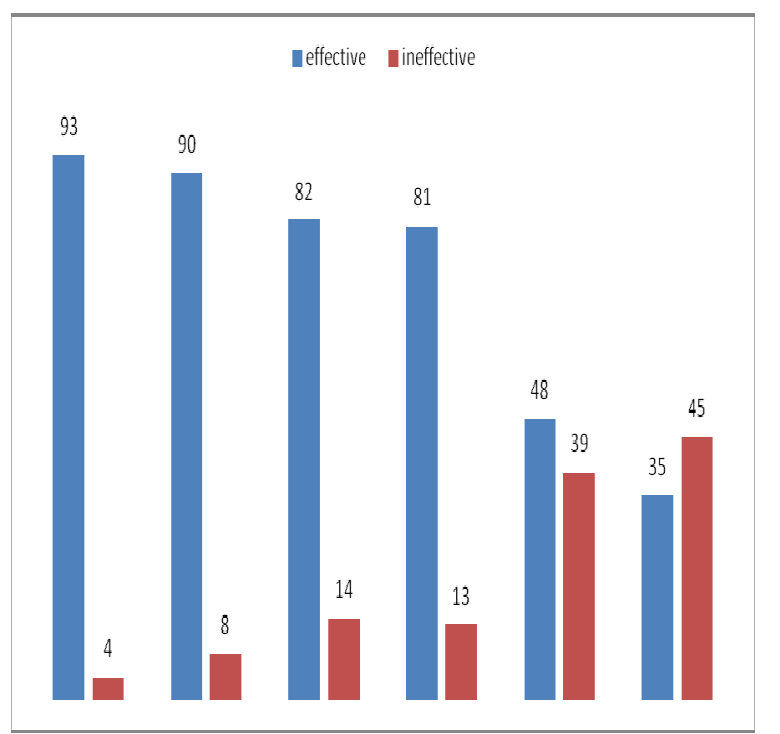

Fig. 2. Assessment of the degree of usefulness of certain opportunities of the electronic course "Mathematics" by students $(\%)$

Data of the survey showed that the following opportunities of the electronic course were considered the most useful:

- continuous access to training materials (93\%),

- opportunity to gain points $(90 \%)$,

- participation in online testing $(82 \%)$,

- opportunity to address to the teacher by means of the computer $(81 \%)$.

According to the survey results, the least useful opportunities were: an opportunity to share the results of the performed tasks for general discussion (35\%) and an opportunity to review others works (48\%).

Students noted that reviewing others works by means of electronic resources failed to replace face-to-face communication with both the teacher and fellow students.

In the research, we tried to analyze what difficulties the students experienced during the work with the electronic course. Most respondents (53\%) noted that they experienced some difficulties because of technical problems (failure in the work of the site of TPU, authorization errors, etc.).

For example, if the student entered the incorrect login or password 3 times, the access to the course was automatically blocked for $30 \mathrm{~min}$.

The students specified the following difficulties they experienced during the work with the course:

- technical problems during the work in the electronic environment (53\%);

- unclear (ambiguous) questions in tests (42\%);

- lack of "live" communication with the teacher $(37 \%)$;

- lack of time for work in the electronic environment $(41 \%)$;

- strictly fixed terms of doing tests (tasks).

An insignificant part of students (1\%) noted that they failed to complete the task in the allotted time. 
More than a half of respondents (51\%) devoted 1 to 3 hours per week to performance of tasks. About $30 \%$ of respondents worked more than 3 hours a week. Besides, some respondents gave the free-form answers: in some days they spent 5-7 hours or had no time at all, etc.

Prior to the experiment, the students were asked whether they found electronic courses useful to better prepare for the exam.

About a third of respondents believed that the electronic course could help them to better prepare for the exam on the subject $(32 \%)$. About a quarter of respondents $(24 \%)$ found it difficult to answer this question. Almost a third (37\%) of respondents believed that electronic courses could not help them to better prepare for the exam.

In addition, some respondents (7\%) gave the freeform answers and comments: all the lectures collected together simplify the process of preparation, the course is useful as a source of additional information, but not as an alternative to traditional classroom learning, it can be used to revise the material and to get additional points, rather no than yes, electronic courses are appropriate for distance learning, but not for intramural training, in case all necessary materials are provided, such training becomes useful as it provides electronic lectures.

Let us note that our experiment caused positive changes in the opinion of respondents about electronic courses.

Most of the students indicated that they systematically studied lectures and submitted their homework via the Moodle platform. About $62 \%$ of the students studied additional materials. And only a third of students interacted with the classmates and teachers through the electronic environment: participated in the discussions, performed the tasks, left comments on the classmates' works.

After the exam, at the end of the semester, more than a half of students in the experimental group (56\%) indicated that the electronic course on mathematics helped them to better prepare for the exam on the discipline. One fifth of respondents $(20 \%)$ told that they could pass the exam without the electronic course. Other respondents found it difficult to answer this question.

However, more than a half of respondents $(58 \%)$ in the experimental group found it necessary to use the electronic courses in all disciplines, in particular, in mathematics and in the disciplines of a natural-science cycle.

\section{Conclusion}

Tomsk Polytechnic University has been using the Moodle platform to organize the process of students' independent learning for the last five years. The experience has shown that Moodle can trigger the cognitive activity of students.

In general, implementation of the virtual learning environment in teaching mathematics and disciplines of a natural-science cycle allows the teacher:

- to effectively organize independent learning of students outside the classroom;
- to avoid the routine checking of homework, tests, and individual tasks;

- to introduce the creative approach to the educational activity;

- to help students know the information sources;

- to receive the data on the students who successfully study materials, and the amount of time they devote to studying this or that subject.

Thus, the organization of learning by means of Moodle had a positive effect on the level of training of first-year students.

\section{References}

1. K. Egan, Teach. Educ., 26, 3 (2015)

2. O. S. Tan, Educ. Res. Pol. Pract., 14, 3 (2015)

3. K. Zgodavova, M. Horvath, Lect. Notes Electric. Eng., 312 (2015)

4. F. Corvalán, G. Muñoz, V. Veas Int. J. Learn. High. Educ., 22, 2 (2015)

5. C. L. Weitze, R. Ørngreen, Electron. J. e Learn., 12, 2 (2014)

6. M. C. Rodriguez-Sanchez, J. A. HernandezTamames, S. Borromeo, Comput. Appl. Eng. Educ. 23, 2 (2015)

7. Y.- H. Wang, S. K.-H. Shih, Int. J. Mob. Commun., 13, 4 (2015)

8. A. Berns, M. Palomo-Duarte, J. M. Dodero, A. Cejas, Lect. Notes Comput. Sci., 8719 (2014)

9. P. Mulholland, S. Anastopoulou, T. Collins, M. Feisst, M. Gaved, L. Kerawalla, M. Paxton, E. Scanlon, M. Sharples, IEEE TLT, 5, 2 (2012)

10. A. Adams, T. Coughlan, Y. Rogers, T. Collins, S. Davies , C. Blake, J. Lea, Int. J. Comp-Supp. Coll., 2 (2011)

11. P. - C. Kao, P. Craigie, SBP J., 42, 1 (2014)

12. R. Faizi, A. A. El Afia, R. Chiheb, IJET, 9, 5 (2014)

13. K. Wong, R. Kwan, K. Leung, F. L. Wang, Int. J. Innovat. Learn., 16, 2 (2014)

14. M. Delgado-Verde, S. Cooper, G.M.-D. Castro, Int. J. Technol. Manage., 69, 2 (2015)

15. L. Stošić, I. Stošić, Comput Hum Behav, 53 (2015)

16. D. Ursutiu, C. Samoila, J. Bergmans, Proceedings ICL, 7017853 (Dubai, 2015)

17. G. Cheng, H.L. Chui, CCIS, 494 (2015)

18. N.Z. Zacharis, Internet High. Educ., 27 (2015)

19. B.F. Klímová, P. Poulová, Proceedings ECEL (2014)

20. L. Xiang-Feng, Proceedings ICICTA (2015)

21. O. N. Efremova, I. V. Plotnikova, A. K. Ustyuzhanina, Procedia Soc. Behav. Sci., 215 (2015)

22. O. N. Imas, V. S. Kaminskaya, A. I. Sherstneva, Proceedings ICL, (Florence, 2015)

23. O. V. Yanuschik, E. G. Pakhomova, Kx. Batbold, Procedia Soc. Behav. Sci., 215 (2015) 